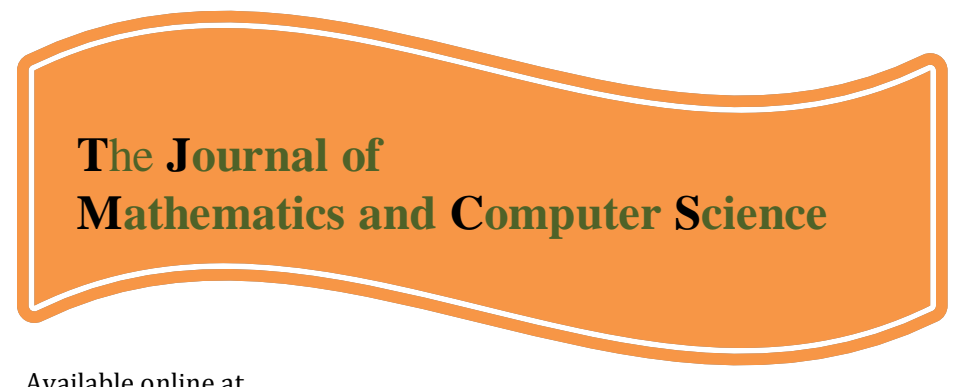

Available online at

http://www.TJMCS.com

The Journal of Mathematics and Computer Science Vol .2 No.4 (2011) 659-666

\title{
Robust Control of Inverted Pendulum Using Fuzzy Sliding Mode Control (FSMC)
}

\author{
Mohamad Reza Dastranj1, Mahbubeh Moghaddas', Kazem Esmaeili Khoshmardan ${ }^{3}$, \\ Assef Zare ${ }^{4}$
}

Islamic Azad University, Gonabad Branch, Iran, Mohamadrezadastranj@gmail.com Islamic Azad University, Gonabad Branch, Iran, Moghaddasm.m@gmail.com Islamic Azad University, Gonabad Branch, Iran, Esmaeilikhoshmardan@gmail.com Islamic Azad University, Gonabad Branch, Iran, Assefzare@gmail.com

Received: July 2010, Revised: October 2010

Online Publication: January 2011

\begin{abstract}
Due to the vast application of inverted pendulum in robust, one of the most important Problems today is robotics and its control. In this paper by using fuzzy sliding control, we have tried to control the inverted pendulum angle by nonlinear equations. No oscillation in response in seen by using this method and the time for achieving a desirable response is appropriate. The results of this simulation have as well as its comparison with the classical controller has been mentioned at the conclusion.
\end{abstract}

Keywords: nonlinear system, fuzzy control, sliding mode, artificial control, inverted pendulum

1, MSC Student Islamic Azad University Gonabad Branch, Iran

2,MSC Student Islamic Azad University Gonabad Branch, Iran

3,MSC Student Islamic Azad University Gonabad Branch, Iran

4, Assistant Professor Islamic Azad University Gonabad Branch, Iran 


\section{Introduction}

There are variety methods for Inverted Pendulum control that are presented since now. The presented methods for Inverted Pendulum control are divided gen erally in three groups. Classic methods such as PID and PI controllers [1,2]. Modern methods (adaptation-optimum...) [3, 4, 5] .Artificial methods such as neural networks and fuzzy and Genetic Algorithm and PSO [6, 7, 8] theory are the presented methods for Inverted Pendulum angle control.

The design method in linear control comprise based on main application the wide span ' of frequency, linear controller has a weak application, because it can't compensate the nonlinear system effect completely.

\section{Modeling an Inverted Pendulum}

The cart with an inverted pendulum, shown below, is "bumped" with an impulse force, F. Determine the dynamic equations of motion for the system, and linearize about the pendulum's angle, theta $=0$ (in other words, assume that pendulum does not move more than a few degrees away from the vertical, chosen to be at an angle of 0 ). Find a controller to satisfy all of the design requirements given below. For this example, let's assume that.

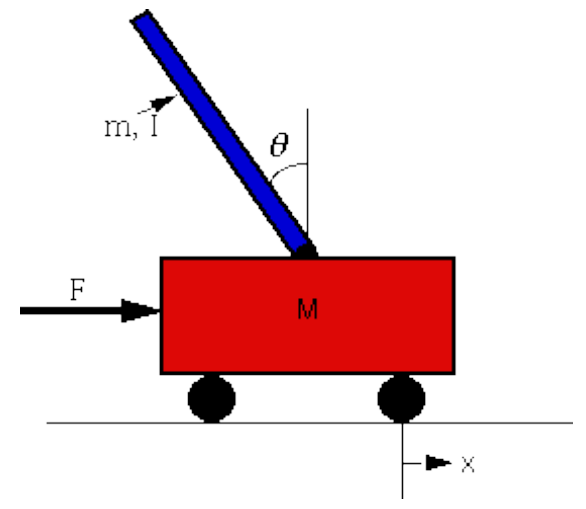

Figure 1.The structure of an Inverted Pendulum

Table 1physical parameters of Inverted Pendulum

\begin{tabular}{|l|l|l|}
\hline $\mathrm{M}$ & mass of the cart & $0.5 \mathrm{~kg}$ \\
\hline $\mathrm{m}$ & mass of the pendulum & $0.2 \mathrm{~kg}$ \\
\hline $\mathrm{b}$ & friction of the cart & $0.1 \mathrm{~N} / \mathrm{m} / \mathrm{sec}$ \\
\hline $\mathrm{l}$ & length to pendulum center of mass & $0.3 \mathrm{~m}$ \\
\hline $\mathrm{I}$ & inertia of the pendulum & $\begin{array}{l}0.006 \\
\mathrm{~kg}^{*} \mathrm{~m}^{\wedge} 2\end{array}$ \\
\hline $\mathrm{F}$ & force applied to the cart & \\
\hline $\mathrm{x}$ & cart position coordinate & \\
\hline theta & pendulum angle from vertical & \\
\hline
\end{tabular}


This system is tricky to model in Simulink because of the physical constraint (the pin joint) between the cart and pendulum which reduces the degrees of freedom in the system. Both the cart and the pendulum have one degree of freedom ( $\mathrm{X}$ and theta, respectively). We will then model Newton's equation for these two degrees of freedom.

$\frac{d^{2} x}{d t^{2}}=\frac{1}{M} \sum_{c a r t} F_{x}=\frac{1}{M}\left(F-N-b \frac{d x}{d t}\right)$

$\frac{d^{2} \theta}{d t^{2}}=\frac{1}{I} \sum_{\text {pend }} \tau=\frac{1}{I}(N L \cos (\theta)+P L \sin (\theta))$

It is necessary, however, to include the interaction forces $\mathrm{N}$ and $\mathrm{P}$ between the cart and the pendulum in order to model the dynamics. The inclusion of these forces requires modeling the $\mathrm{x}$ and y dynamics of the pendulum in addition to its theta dynamics. Generally, we would like to exploit the modeling power of Simulink and let the simulation take care of the algebra. Therefore, we will model the additional $\mathrm{x}$ and $\mathrm{y}$ equations for the pendulum.

$$
\begin{aligned}
& m \frac{d^{2} x_{p}}{d t^{2}}=\sum_{p e n d} F_{x}=N \\
& \Rightarrow N=m \frac{d^{2} x_{p}}{d t^{2}} \\
& m \frac{d^{2} y_{p}}{d t^{2}}=P-m g \\
& \Rightarrow P=m\left(\frac{d^{2} y_{p}}{d t^{2}}+g\right)
\end{aligned}
$$

However, xp and yp are exact functions of theta. Therefore, we can represent their derivatives in terms of the derivatives of theta.

$$
\begin{aligned}
& x_{p}=x-L \sin (\theta) \\
& \frac{d x_{p}}{d t}=\frac{d x}{d t}-L \cos (\theta) \frac{d^{2} \theta}{d t^{2}} \\
& \frac{d^{2} x_{p}}{d t^{2}}=\frac{d^{2} x}{d t^{2}}+L \sin (\theta)\left(\frac{d \theta}{d t}\right)-L \cos (\theta) \frac{d^{2} \theta}{d t^{2}} \\
& y_{p}=L \cos (\theta) \\
& \frac{d y_{p}}{d t}=-L \sin (\theta) \frac{d \theta}{d t} \\
& \frac{d^{2} y_{p}}{d t^{2}}=-L \cos (\theta)\left(\frac{d \theta}{d t}\right)^{2}-L \sin (\theta) \frac{d^{2} \theta}{d t^{2}}
\end{aligned}
$$


These expressions can then be substituted into the expressions for $\mathrm{N}$ and $\mathrm{P}$. Rather than continuing with algebra here, we will simply represent these equations in Simulink. Simulink can work directly with nonlinear equations.

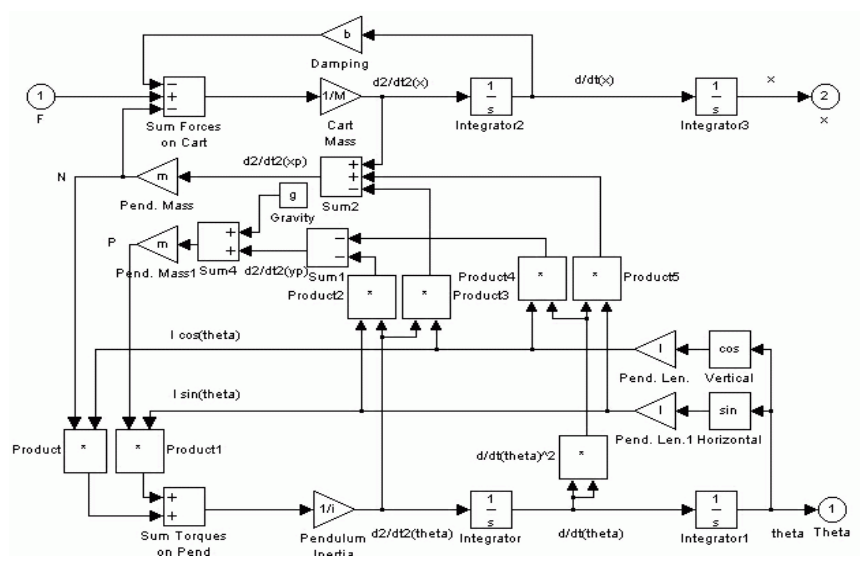

Figure 2.The block diagram of an Inverted Pendulum

\section{Sliding Mode Controller}

Nonlinear system control that its model isn't clear carefully works with two methods:

(1).Robust control methods.

(2).Adaptive control methods.

In control view, uncertainly in modeling is divided in two main kinds:

(1).Non certainly in existent Para meters in model

(2).Estimating the lower step for system and being UN modeled dynamics in the estimating model.

Sliding control is one of the designed modes for robust control that make access to system desired application estimating system in model.

The major idea of this method is the controlling of nonlinear first grade system is easier than $\mathrm{n}$ grade system control in spite of uncertainly.

But this function maybe cause the control law with more energy that is not practicable implement station. Sliding mode is really compromise between modeling and suitable operation with inaccurate design.

We consider the nonlinear system model in this rule:

$X^{n}=f(x)+b(x) u$

That $\mathrm{F}(\mathrm{x})$ is nonlinear function, its high boundary characterized as $\mathrm{X}$ function. $\mathrm{B}(\mathrm{x})$ is a continuous function that its high and low boundaries characterized by $\mathrm{X}$ function.

The good of finding $\mathrm{X}$ is in this way that in $\mathrm{g}(\mathrm{x}) \mathrm{F}(\mathrm{x})$ function we can follow the desirable mode in spite of uncertainly. 
$\widetilde{X}=X-X_{d}=\left[\tilde{X}, \widetilde{X}^{+}, \ldots, \widetilde{X}^{n-1}\right]$

In ideal state

$\tilde{X}=0$

Sliding surface equation defines as below:

$s=e^{\prime}+\alpha_{1} e+\alpha_{2} \int e d t$

Because of the signals of control that gain with this designing method has limited energy, it is necessary to:

$X_{d}(0)=X(0)$

In other word:

$S(X, t) \equiv 0$

$\frac{1}{2} \frac{d S^{2}}{d t} \leq-\eta|S|$

In designing, the control low on $\mathrm{S}(\mathrm{t})$ continuously is noticed in cause we should concentrate to carelessness in model in sliding surface and reduced the chattering effect.

We can write the system's dynamics when in some situation they are in sliding state.

$$
S^{\prime}=0
$$

The gained control signals for this system are as below:

$U=k_{1} \times$ out $_{f u z z y} \times S$

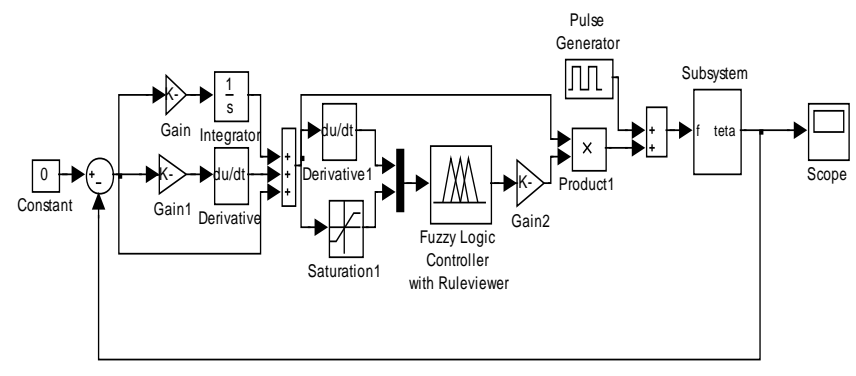

Figure 3.simulink block diagram of FSMC

Fuzzy controls are designed based on created sliding surface and sliding surface changes. All of the fuzzy rules collection came in Table II 
Table2. Fuzzy Rule

\begin{tabular}{|l|l|l|l|l|l|}
\hline $\boldsymbol{d} S / \boldsymbol{S}$ & $\boldsymbol{N B}$ & $\boldsymbol{N S}$ & $\mathrm{ZE}$ & $\boldsymbol{P S}$ & $\boldsymbol{P B}$ \\
\hline $\boldsymbol{N}$ & $\boldsymbol{B}$ & $\boldsymbol{B}$ & $\mathrm{M}$ & $\boldsymbol{S}$ & $\boldsymbol{B}$ \\
\hline $\boldsymbol{Z}$ & $\boldsymbol{B}$ & $\mathrm{M}$ & $\boldsymbol{S}$ & $\boldsymbol{M}$ & $\boldsymbol{B}$ \\
\hline $\boldsymbol{P}$ & $\boldsymbol{B}$ & $\boldsymbol{S}$ & $M$ & $B$ & $B$ \\
\hline
\end{tabular}

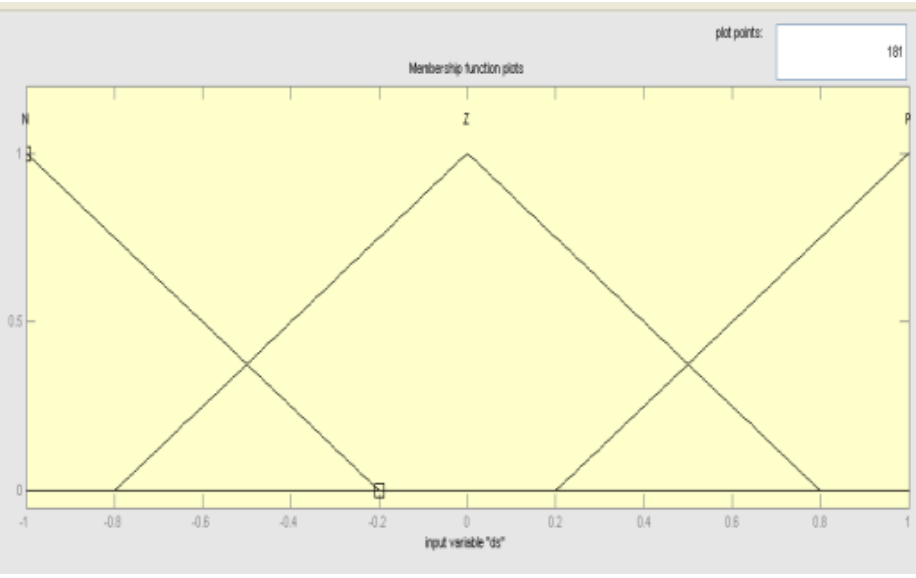

Figure 4.Membership functions for (s) normalized inputs

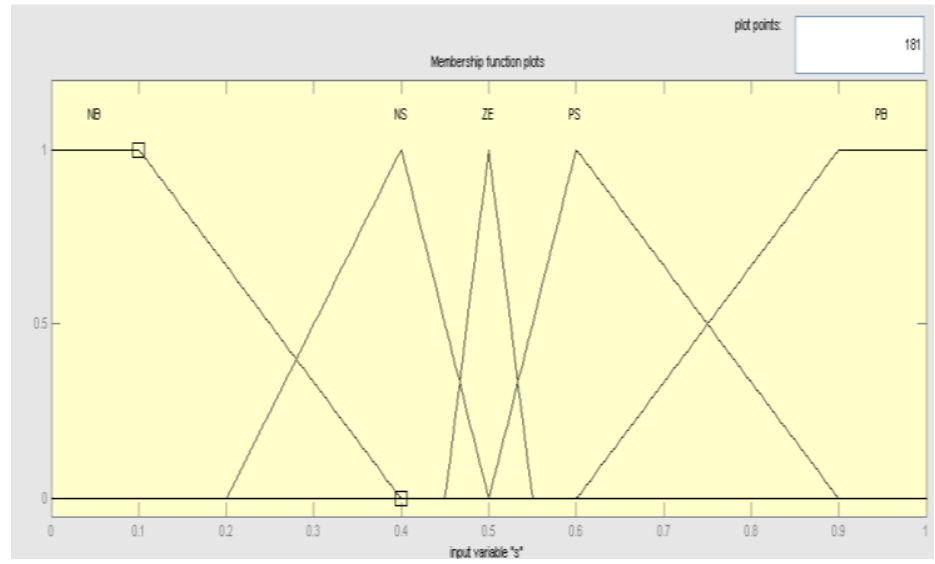

Figure 5.Membership functions for (ds/dt) normalized inputs

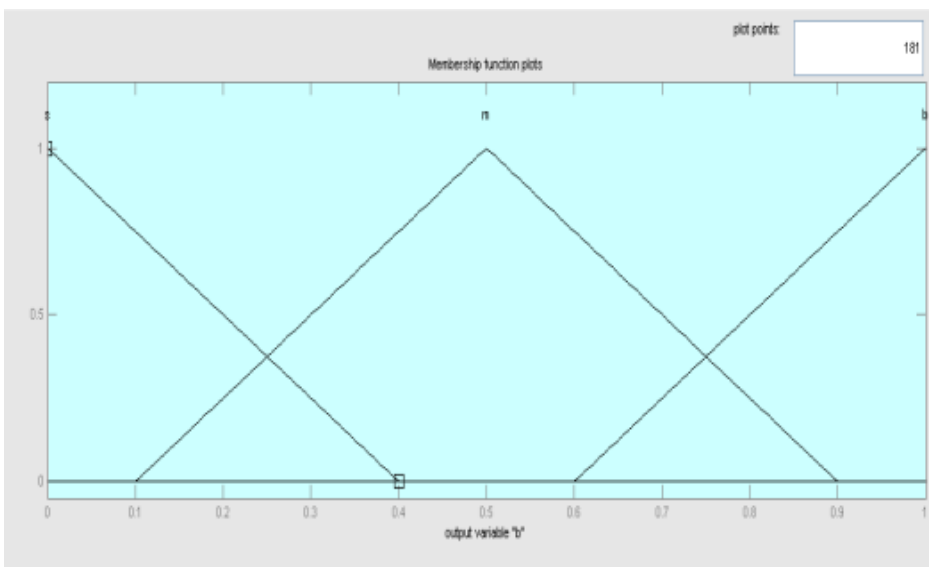

Figure 6.Membership functions for (out fuzzy) normalized outputs

\section{Conclusion}

In this paper, a robust control system with the fuzzy sliding mode controller and the additional compensator is presented for an Inverted Pendulum position control. According to the simulation results, the FSMC controllers can provide the properties of insensitivity and robustness to uncertainties and external disturbances, and response of the Inverted Pendulum for FSMC controllers against uncertainties 
and external disturbance is the same Fuzzy sliding mode controller gives a better response to system than the fuzzy and classical PID controllers.

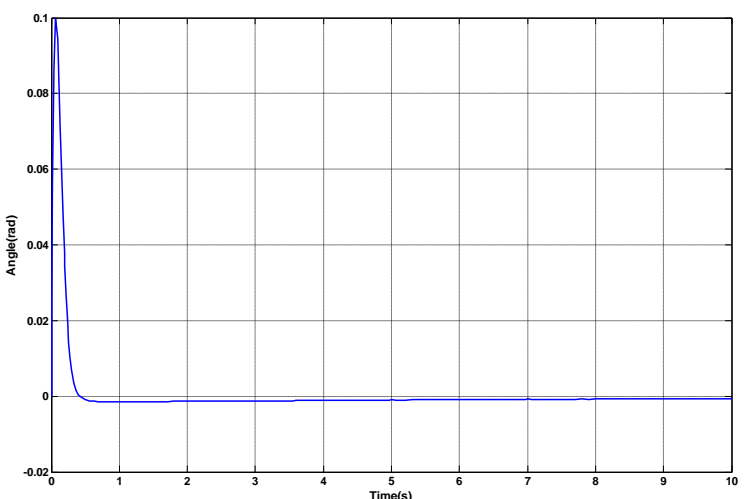

Figure 7.Inverted pendulum rod angle for initial 0.1 radians

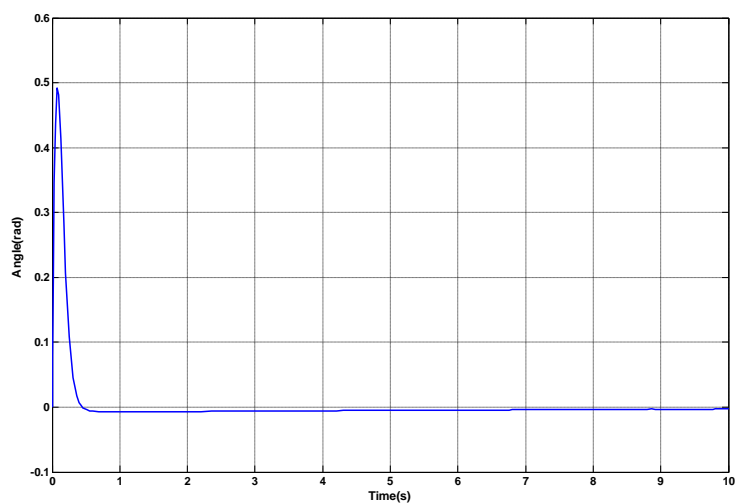

Figure9.Inverted pendulum rod angle for initial 0.5 radians

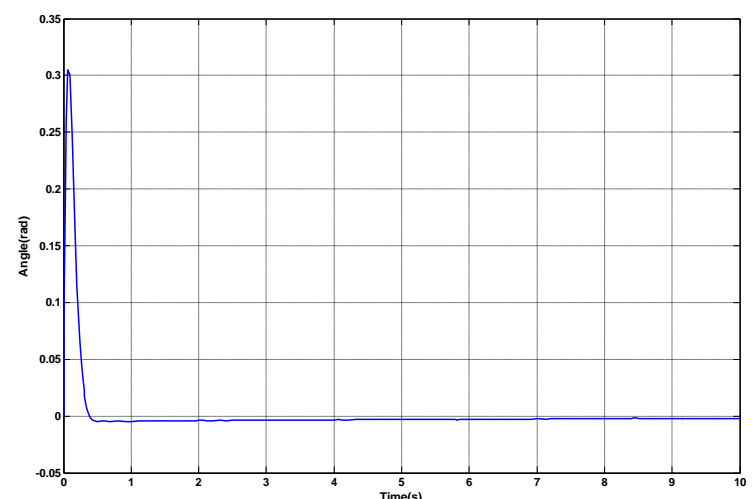

Figure 8.Inverted pendulum rod angle for initial 0.3 radians

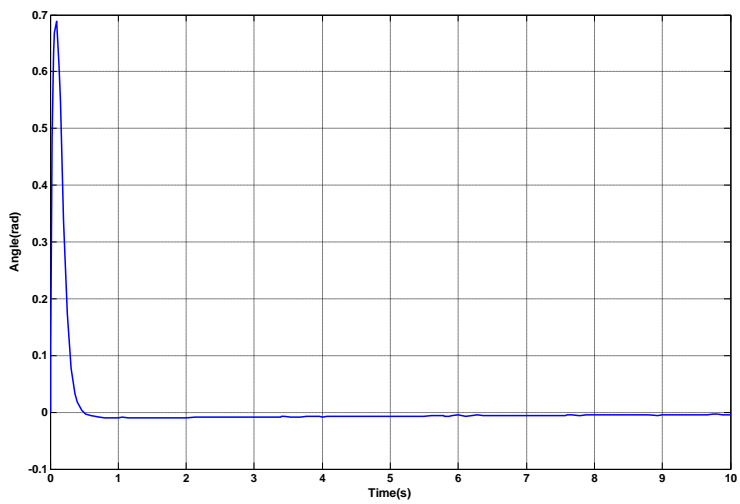

Figure10.Inverted pendulum rod angle for initial 0.7 radians

\section{References}

[1].JIA Nuo, WANG Hui. Nonlinear Control of an Inverted Pendulum System based on sliding mode method. ACTA Analysis Functionalis applicata, 2008, 9(3): pp.234-237.

[2].O. Tolga Altinoz, A. Egemen Yilmaz, Gerhard Wilhelm Weber Chaos Particle Swarm Optimized PID Controller for the Inverted Pendulum System 2nd International Conference on Engineering ptimization September 6-9, 2010, Lisbon, Portugal.

[3].Wu Wang Adaptive Fuzzy Sliding Mode Control for Inverted Pendulum Proceedings of the Second Symposium International Computer Science and Computational Technology (ISCSCT '09) uangshan, P. R. China, 26-28, Dec. 2009, pp. 231-234. 
[4].Viroch Sukontanakarn and Manukid Parnichkun, "Real-Time Optimal Control for Rotary Inverted Pendulum, "American Journal of Applied Sciences 6 (6): 1106-1115, 2009 ISSN 15469239 (C) 2009 Science Publications.

[5].Alexander Bogdanov Optimal Control of a Double Inverted Pendulum on a Cart Technical Report CSE-04-006 December 2004.

[6].T. Sugie, and K. Fujimoto, "Controller design for an inverted pendulum based on approximate linearization," Int. J. of robust and nonlinear controls, vol. 8, no 7, pp. 585-597, 1998.

[7]Shin-ichi Horikawa, Masahiro Yamaguchi, Takeshi Fuzzy Control for Inverted Pendulum Using Fuzzy Neural Networks January 10, 1995

[8].Zadeh, I.H. and S. Mobayen, "PSO-based controller for balancing rotary inverted pendulum," J.AppliedSci.,16:2907-2912 2008.

[9].J. Lam, "Control of an Inverted Pendulum", University of California, Santa Barbara, 10 June 2004 Yasar Beceriklia,_,1, B. Koray Celikb Fuzzy control of inverted pendulum and concept of stability using Java application Mathematical and Computer Modeling 46 (2007) 24-37 